\title{
Discussion on the Elements of Modern Agriculture Sustainable Development
}

\author{
Chunjiang Zhư ${ }^{1, a}$, Rujiu Luo ${ }^{2, b}$ \\ ${ }^{1}$ School of Public Administration,Lianyungang Technical College, Lianyungang, Jiangsu Province, \\ China, 222006 \\ ${ }^{2}$ Department of Basic Courses,Lianyungang Technical College, Lianyungang, Jiangsu Province, \\ China, 222006 \\ ajszcj@126.com, brujiu.luo@gmail.com
}

\begin{abstract}
Keywords: modern agriculture; sustainable development; element model; countermeasure Abstract. The development of modern agriculture should be guided by the theory of sustainable development, and should be based on the idea of harmonious coexistence of man and nature. Starting from the connotation of sustainable agricultural development, this paper constructs a element of modern agriculture sustainable development based on agricultural production factors, government policy, market environment and related industrial factors, and puts forward countermeasures on agricultural infrastructure construction, agricultural policy support, agricultural industry level, agricultural technology innovation ability, personnel quality and market mechanism, so as to realize the sustainable development of modern agriculture.
\end{abstract}

\section{Background and research significance}

Agriculture is an important industrial sector of national economy, which provides the eternal power for the human society civilization development.However, since human beings has entered the industrial civilization in recent centuries, in the process of transforming natural resources into the products needed by mankind, they had no self-control of natural resources consumption, and engaged in predatory development, which seriously affected the sustainable development of agriculture, and exacerbated the problems of agricultural development. This does not comply with the requirements of the scientific development concept, which restricts the development of human civilization, and industrial civilization is the process of creating a model of development is unsustainable[1]. Only by improving the competitiveness of agricultural products, speeding up the transformation of agricultural scientific and technological achievements, promoting the upgrading of agricultural technology, optimizing agricultural industry structure, rationally utilizing modern agricultural science and technology, strengthening rural cultural construction and policy system construction, can we realize the sustainable development of modern agriculture. Therefore, it is very necessary to study the elements of modern agricultural sustainable development, which is bound to play an important role in promoting the sustainable development of modern agriculture with Chinese characteristics.

\section{Sustainable development theory}

The formation and development of the thought of sustainable development can be said that from the last century 60 's[2]. American scientist Rachel Carson's famous, Silent Spring, is the voice of the earth in the dark, awakening people's environmental awareness. Its advent marked the beginning of human concern about the ecological environment[3]. 
In 1980, the International Union for the Conservation of Nature (IUCN) issued World Conservation Strategy, and in which some ecologists first put forward the concept of "sustainable development" in the outline, containing these concepts of the integration of resource conservation and development, maximizing the enduring benefits of the present generation, and maintaining its potential to meet the needs and aspirations of future generations.

Sustainable development has been defined in many ways, but the most frequently quoted definition is from Our Common Future, also known as the Brundtland Report "Sustainable development is development that meets the needs of the present without compromising the ability of future generations to meet their own needs"[4].

\section{The element model of modern agriculture sustainable development}

In 1988, United Nations Food and Agriculture Organization (FAO) formulated a policy document on "sustainable agricultural production: requirements for international agricultural research". In 1991, FAO and the Dutch government held an international conference on agriculture and the environment in Den Bosch, and adopted the historic "Den Bosch Declaration". The new concept of "Sustainable Agriculture and Rural Development (SARD)", as proposed in the Declaration, is adopting a way of using and maintaining the natural resource base, and implementing technological change and institutional reform to ensure that the demand for agricultural products is constantly being met by contemporary human beings and their descendants. This sustainable development, including agriculture, forestry and fisheries, protects the genetic resources of land, water and animals and plants, makes the environment not degraded, the technology applied properly, economically viable and socially acceptable[5]. It is characterized by two aspects: Firstly, to link agricultural sustainable development with rural development for the first time; Secondly, to seek to combine the various agricultural sustainability factor systems into integrated networks to make them more feasible.

From United Nations Food and Agriculture Organization (FAO) definition of sustainable agricultural development, it can be seen that the sustainable development factors of modern agriculture relate to factors of agricultural production, government policy, market environment and related industries.

So we can build a model of modern agricultural sustainable development elements as shown in Figure 1 from the definition of sustainable agricultural development of United Nations Food and Agriculture Organization (FAO).

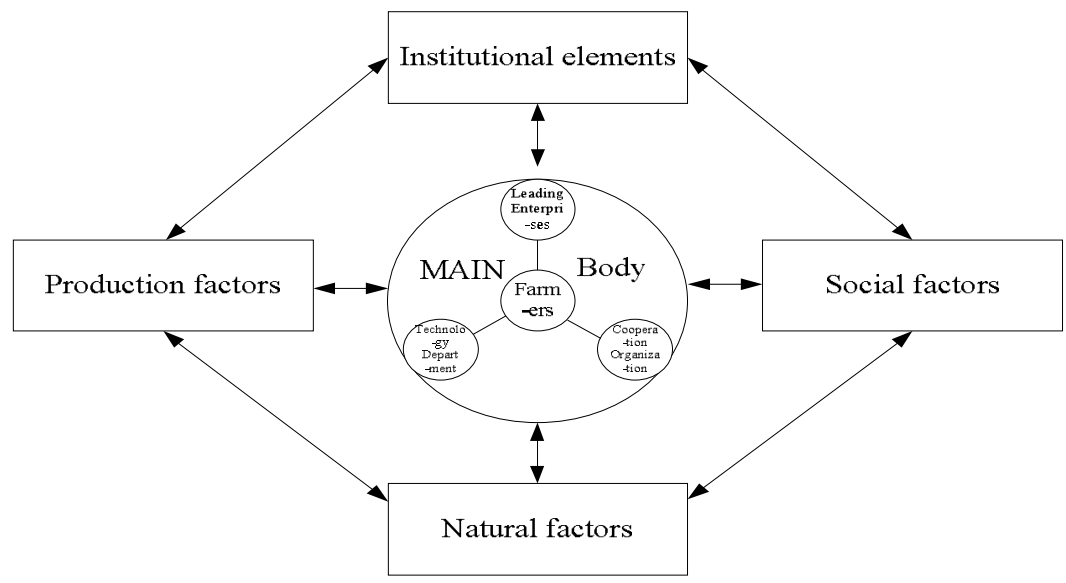

Fig. 1 modern agricultural sustainable development element model 


\section{Analysis on the elements of modern agriculture sustainable development}

From the analysis of the elements of modern agricultural sustainable development model, we can see that there are still many practical problems in agricultural sustainable development which include that the agricultural foundation is still weak, the agricultural policy is not perfect, the agricultural industry level is low, the agricultural technology innovation ability is not enough, the quality of the personnel is not high, and the market mechanism is imperfect and so on. Not to solve the basic problems of agriculture, there are no agricultural modernization, and no agricultural sustainable development.

\section{(1)On agricultural foundation}

In 2017, the National Bureau of Statistics data show that the annual grain cultivation area of 112.22 million hectares, 810,000 hectares reduced than the previous year, the national tractor 26.9 million units, irrigation and drainage power machinery 14.31 million units, and the number of irrigation water ponds and reservoirs that can be used 3.49 million. On the whole, the mechanization of agriculture is not high, and the agricultural infrastructure construction is relatively backward. These factors seriously restrict the sustainable development of agriculture and affect the modernization of agriculture.

Fortunately, the $18^{\text {th }}$ and $19^{\text {th }}$ National Congress of the Communist Party put forward the national infrastructure construction and social undertakings development on rural areas.By improving the agricultural infrastructure, the face of the countryside is changed and the power of agricultural development is enhanced. Under the guidance of the concept of green development, comprehensive conservation of resources promotes effectively, the intensity of energy resources consumption declines significantly, and the major ecological protection and rehabilitation projects are progressing smoothly, which realize the historical leap of agricultural and rural development, and sustainable development of modern agriculture.

\section{(2)On agricultural policy}

The sustainable development of modern agriculture can not be separated from the National macro policy environment. In 2018, the Central Document No. 1 announces the comprehensive deployment and implementation of rural revitalization strategy to accelerate the sustainable development of modern agriculture. Therefore, we should improve the system of agricultural support and protection, adhere to the priority development of agricultural and rural areas, and improve the institutional mechanism and policy system of urban-rural integration. We deepen agricultural products and storage systems and price formation mechanism reform, and improve the benefit compensation mechanism of the main grain producing areas. We fully implement the special protection system of permanent basic farmland, deepen the reform of rural land system, and implement the policy of extending the second round of land contract for 30 years. Through the national policies in agricultural industry, the new leap-forward development of modern agriculture is promoted.

(3) On agricultural industry level

Agriculture is one of the traditional industries in China, which plays an important role in realizing the industrialization process. On the one hand, due to the long-term extensive production, the agricultural production has consumed the massive energy and the resources, and has restricted the traditional industry sustainable development[6]. On the other hand, the current low level of agricultural specialization has not fully formed a professional level, and can not support the rapid development of modern agricultural industry. 
Therefore, the government should give preferential policy to support agricultural leading enterprises, demonstration zone and agricultural cooperative economic organizations in the fields of credit, capital and taxation, and vigorously develop aquaculture processing and sales, food processing, animal husbandry, food processing, vegetable processing, wood industry and other agricultural industries. The leading enterprise, the agricultural high and new demonstration zone itself should give full play to own superiority, carry on the industrial science and technology innovation, open up the market, expand the scale of the leading enterprise and the demonstration zone, and play the leading to drive the demonstration the function to enhance the agricultural industrialization management, and the specialization level.

(4) On agricultural technology innovation ability

At present, most agricultural enterprises are still lagging behind in technology and equipment. The low level of the processing of agricultural products, the low scientific content and the low degree of agricultural informatization can not provide permanent impetus for the modernization of agricultural industry.

So first of all, the government should increase investment in agricultural research and support agricultural science and technology projects, which provides a good policy environment for agricultural science and technology innovation. Secondly, we should improve the application level of agricultural scientific and technological achievements, intensify the implementation of scientific research and deepen the innovation of agricultural science and technology management system. Thirdly, the government should strengthen the support in the field of agricultural informatization. We can choose the model base of agricultural industry informatization in the relatively economic strength areas. Especially we introduce and strengthen the construction of the agricultural informatization talents, so as to promote the rapid development of the agricultural industry information. The state should give support to agricultural science and technology innovation activities of agricultural production and management departments, and guide the agricultural production and management departments on the road of scientific and technological innovation application.

(5) On the quality of employees

Agricultural modernization construction needs a large number of agricultural science and technology workers who engage in grass-roots and rural labor force for agricultural production and operation activities. But both qualities are relatively low at present, so we should cultivate new-type agricultural science and technology workers and professional farmers. On the one hand, we should do well the retraining and re-education work of agricultural science and technology workers, improve the treatment of agricultural technicians, and create a good working environment. On the other hand, we should strengthen the construction of rural professional talent team. According to various characteristics of agricultural workers, we will give a different learning training activities. If farmers are not well educated, they can start from literacy. For farmers with relatively higher education,we can set up agricultural technology interest classes to improve the comprehensive quality and ability.

(6) On market mechanism

At present, the uncertainty of the market environment of agricultural industry makes the development of modern agricultural industry necessarily exist some market risks. Therefore, we must improve the property right system and factor market allocation as the focus, and do the following work in several aspects.Firstly, the government formulates preferential policies to absorb social funds and foreign investment in agricultural industry input, and establishes a market-wide compensation mechanism for diversification.Secondly, we should form the "Company + Base + 
Cooperation Organization + Peasant Household" interest communities to improve the ability of agricultural enterprises or peasants to resist market risk.Thirdly, because the agricultural industry is relatively weak, it is important to form the agricultural investment based on industry-assisted agriculture, industry-promoted agriculture, and industry-driven agriculture to promote the agricultural industry, so as to realize the historic leap of agricultural development.

\section{Conclusion}

Modern agricultural sustainable development should seize the strategic opportunity of "One Belt, One Road". Based on the theory of sustainable development and the idea of harmonious coexistence between man and nature, this paper analyzes the factors of agricultural production, government policy, market environment and related industries in the sustainable development of modern agriculture. It is considered that only improving in the aspects of agricultural infrastructure construction, agricultural policy support, agricultural industry level, agricultural technology innovation ability, personnel quality and market mechanism, can we solve the problems faced by modern agricultural development and realize the sustainable development of modern agriculture.

\section{Acknowledgements}

This work was financially supported by Jiangsu Province social science research project ( 15SRA-10 ) ,and sponsored by Lianyungang “521” High-level Talents Program.

\section{References}

[1] Li Jing. Sustainable Development in the View of Ecological Civilization[D]. Shandong University,2007

[2] Brown L R. and Shaw. Six Steps to Sustainable Society. Worldwatch Institiute, Washington DC, 1982.

[3] Rachel Carson, Silent Spring[M]. Jilin People's Publishing House, 1997

[4] Zhu Chunjiang, Luo Rujiu, Ma Huimin. Agricultural Industry Cluster Sustainable Development Based on the Perspective of the Scientific Outlook on Development[J]. Advanced Materials Research Vols. 524-527 (2012) pp 3563-3568

[5] Department of Agricultural Resources Division of the Ministry of Agriculture. Technology and application of sustainable agriculture and rural development [M]. Beijing: China Agricultural Science and Technology Press, 1996

[6] Liu Shaowei, Li Fengju. Promoting the transformation of "zoology" of traditional agriculture---the construction of agricultural eco-industrial chain network [J]. Tianjin Agricultural Science, 2011 (3): 81 